\title{
Effects of learning addition and subtraction in preschool by making the first ten numbers and their relations visible with finger patterns
}

\section{Angelika Kullberg $^{1}$ (D) Camilla Björklund ${ }^{2}$ - Irma Brkovic ${ }^{1} \cdot$ Ulla Runesson Kempe $^{3,4}$}

Published online: 10 December 2019

(C) The Author(s) 2019

\begin{abstract}
In this paper, we report how 5-year-olds' arithmetic skills developed through participation in an 8-month-long intervention. The intervention program aimed to enhance the children's ways of experiencing numbers' part-part-whole relations as a basis for arithmetic skills and was built on principles from the variation theory of learning. The report is based on an analysis of assessments with 103 children (intervention group $n=65$ and control group $n=38$ ) before and after the intervention and a follow-up assessment 1 year after the intervention. Our findings show that the learning outcomes of the intervention group were significantly higher compared to those of the control group after the intervention and that differences between the groups remained even 1 year after the intervention. In particular, the results show that children participating in the intervention group learned to recognize and use part-part-whole relations in novel arithmetic tasks.
\end{abstract}

Keywords Preschool · Addition · Subtraction · Part-part-whole · Variation theory · Intervention · Arithmetic

An earlier draft of the paper was presented at the International Group for the Psychology of Mathematics Education Conference 2018 in Umeå, Sweden.

Angelika Kullberg

Angelika.Kullberg@gu.se

1 Department of Pedagogical, Curricular and Professional Studies, University of Gothenburg, Box 300, 40530 Gothenburg, Sweden

2 Department of Education, Communication and Learning, University of Gothenburg, Box 300, 405 30 Gothenburg, Sweden

3 School of Education and Communication, Jönköping University, 55318 Jönköping, Sweden

4 Wits School of Education, University of the Witwatersrand, Johannesburg, South Africa 


\section{Introduction}

In this study, we aim to test the effects of an intervention based on a structural approach to numbers on 5-year-olds' abilities to solve arithmetic tasks and to describe the results of this intervention in terms of learning outcomes. We base the intervention on the idea that children need to experience numbers as part-part-whole relations and simultaneously experience the cardinal and ordinal meaning of numbers in order to solve arithmetic tasks. Addition and subtraction consist of additive relationships constituted of part-part-whole relations, and the ability to discern and handle this structure has been described as critical for children's development of powerful arithmetic strategies and skills (Baroody, 2016; Fritz, Ehlert, \& Balzer, 2013; Resnick, 1983). Previous studies have also found that finger patterns can be beneficial for children's experience of part-part-whole relations (Brissiaud, 1992; Neuman, 1987, 2013). Thus, the intervention, based on variation theory (Marton, 2015) and designed in collaboration with preschool teachers to promote early arithmetic skills, aimed at using finger patterns for the first ten numbers as a means to structure numbers' part-part-whole relations. Our research goal in this paper is foremost to investigate the effects of the intervention by answering the following questions: (i) Does making the first ten natural numbers and their relations visible through finger-based training increase basic addition and subtraction skills? and (ii) How does the intervention group's development compare to that of a control group immediately after the intervention and 1 year after the intervention? We use oral task-based assessments with 103 children, from an intervention and a control group, to establish the children's knowledge of numbers and arithmetic tasks as well as the learning outcome of the intervention.

\section{Background}

Our intervention project (FASETT) takes its point of departure in the earlier work of Neuman $(1987,2013)$ based on a structural approach to numbers: Preschool children (5-year-olds) who are taught to handle numbers as part-part-whole relations using finger patterns, we argue, learn to solve arithmetic tasks in more powerful ways that entail conceptual knowledge and thus will have long-lasting effects. Research shows that children who learn certain strategies when encountering addition and subtraction tasks are reluctant to change their strategies, even to more efficient ones (Cheng, 2012). This implies that both children's early encounters with powerful ways to solve arithmetic tasks and early interventions are important for further learning opportunities and the development of more advanced skills.

International research from the past three decades has given a comprehensive picture of general learning trajectories of arithmetic skills (e.g., Clements \& Sarama, 2009). It has been shown that children use different counting strategies with increasing complexity (Carpenter \& Moser, 1982; Fuson, 1992; Verschaffel, Greer, \& De Corte, 2007) that help them reason their way to a solution. Many studies of young children's acquisition of basic numerical skills largely emphasize early counting skills, from which children learn to add and subtract numbers, where one set of items is added to another or subtracted from a larger set (Carpenter \& Moser, 1982; Fuson, 1988, 1992). Following this line of reasoning, children are observed developing counting skills in addition by "counting all" and "counting on" and in subtraction by "counting down" (Fuson, 1988), to find the answer. Murata and Fuson (2006) argue that "very young children typically see a quantity as an aggregate of single units, and 
thus they need to count when finding the total" (p. 432). Children then supposedly discover the relations between numbers and are eventually able to find the missing addend in arithmetic tasks, such as $3+_{-}=8$. However, merely counting on from 3 will not illuminate the answer, if the child does not know that 8 refers to a whole made up of 3 and another unknown part. The crucial part in the development of arithmetic skills seems to be realizing that 3 is one part of 8 and that a missing part can be found if the task (addition as well as subtraction) is seen in terms of a part-part-whole relation (Baroody, 2016). Counting may help the child solve the task at hand, but does not promote his or her full potential for mathematical problem solving since counting does not emphasize number relations, such as the triad of numbers 3-5-8 in the example above. An overemphasis on counting strategies may even delay children's development of more advanced mathematical skills, since "preschool children who receive continuous encouragement when using counting strategies are reluctant to try the new more advanced decomposition strategy" (Cheng, 2012, p. 30).

Research thus suggests that counting single units as the primary strategy for solving arithmetic tasks may not prepare children for developing more advanced computational skills that involve, for example, the base ten structure. This is confirmed by Gray, Pitta, and Tall (2000), who found that children who were less able to solve arithmetic problems in the primary school years also relied extensively on counting procedures. The question is, then, whether it is possible to impose the more powerful structuring approach to solving arithmetic tasks in the early years. In Cheng's (2012) intervention with 5- to 6-year-olds, it was indeed shown that it is possible to teach children to use decomposition strategies rather than counting strategies. Decomposing numbers is furthermore known to advance children's ability to handle arithmetic tasks, since it means splitting numbers and combining them in ways that make the task easier to comprehend (altering $8+5$ to $8+(2+3)$, where $8+2$ is easily seen as 10 , and then adding the remaining part, 3 , thus relying on a part-part-whole awareness of numbers. As Cheng concludes, success relies on children first having knowledge of the part-part-whole relation of the first ten natural numbers. Neuman $(1987,2013)$ argues that an inability to recognize numbers as part-part-whole relations may be a cause of not learning number facts, which leads to the need for cumbersome strategies, such as "double-counting" of single units (cf. Baroody, 1987; Fuson, 1982). In line with Cheng's (2012) conclusion, we suggest, that children's number concepts can be developed through activities that do not necessarily involve sequential counting (see also Brissiaud, 1992; Wright, 1994).

In order to learn to see numbers as part-part-whole relations, children have to find ways to structure arithmetic tasks, for example with concrete manipulatives or fingers. There are many observations of young children (preschoolers) using and creating diverse and creative solutions and strategies in problem solving, including counting fingers, finger patterns, verbal counting, retrieval, and derived facts (Clements \& Sarama, 2007). Young children are thus able to enact a variety of strategies and resources to facilitate their finding of ways to deal with an arithmetic task. Fuson (1982, 1988) and Baroody (1987) provide us with extensive observations of children's ways of using fingers, mostly as resources for keeping track of counted units. Fingers are useful for procedural purposes (keeping track), but are insufficient if they are not developed into conceptually based ways of encountering more advanced arithmetic tasks (Steffe, Thompson, \& Richards, 1982). According to Moeller, Martignon, Wesselowski, Engel, and Nuerk (2011) (based on a summary of neuro-scientific studies), successful finger-based counting and arithmetic serve as building blocks for numerical and arithmetical development, which is assumed to be due to the structure of numbers that finger patterns can emphasize to the child. 
In an early study, Neuman $(1987,2013)$ proposed a distinct use of finger patterns to allow children to discern number structures that might otherwise be difficult to discover and act upon. Children who use finger patterns that represent composite sets of numbers in a part-partwhole relation were found to be more likely to develop successful strategies for solving arithmetic problems, whereas those who use fingers only for keeping track of counted numbers rarely experience the necessary part-part-whole relation that facilitates fluent operations with numbers (cf. Björklund, Kullberg, \& Runesson Kempe, 2019). Neuro-scientific findings support the idea that children's use of fingers can enhance arithmetic learning (e.g., Butterworth, 1999; Butterworth, Varma, \& Laurillard, 2011), but as Sinclair and Pimm (2015) also point out, there are important differences in how children use their fingers in arithmetic tasks - to count on or to count with. In general, the difference between the two approaches, we suggest, is experiential in that children may use finger patterns to represent the quantity of a set (Brissiaud, 1992) and thus structure numbers in a visual way informed by their cardinal meaning. This way of using fingers in arithmetic problem solving means that numbers are experienced as cardinal sets and the structuring of numbers as a part-part-whole relation facilitates a conceptual understanding of numbers, which in the literature is preferred to procedural skills only (Threlfall, 2002).

Thus, there are significant differences in approaches to solving arithmetic tasks and in how resources are used to expand the repertoire of strategies children have learned. Threlfall (2002) highlights that children's awareness and knowledge of numbers in a task are related to how they choose to solve the task. This is consistent with the findings of Neuman $(1987,2013)$, who observed young children expressing very different arithmetic skills when entering formal education, differences that stem from varying ways of experiencing numbers. The way of experiencing numbers is, in her line of reasoning, assumed to have an impact on what children are able to do with numbers (e.g., their arithmetic skills). It is thus what children learn about numbers and how to deal with arithmetic tasks that becomes critical for their further development. Altogether, this gives us support in investigating whether early intervention specifically aiming to promote $a$ structural way of experiencing numbers, rather than counting, is possible, and what learning outcomes such an intervention would entail.

\section{The intervention program}

Intervention programs in early years education have provided the field of knowledge with important findings regarding successful paths for research-based activities and experiences for preschool mathematics (Clements \& Sarama, 2011). An overview of preschool interventions indicates that successful interventions target a single content strand, have continuity in teaching, design programs for the preschool education context, and have a framework that takes into consideration individual differences (Wang, Firmender, Power, \& Byrnes, 2016). Our intervention is focused on a limited number range (the first ten natural numbers) and a structural approach to teaching arithmetic problem solving and is based on an iterative process of a continuous development of teaching activities in close collaboration with preschool teachers. In addition, we have a solid theoretical framework that provides direction for what the intervention should focus on and draws attention to the learners' perspective. The intervention therefore has a design that follows the conditions outlined by Wang et al. (ibid.) for a successful outcome. 
The present study takes its starting point in the variation theory of learning (Marton, 2015), a theoretical approach that describes learning as the development of ways of experiencing phenomena. In accordance with this theory, children in our intervention program need to learn to experience numbers as part-part-whole relations and simultaneously experience the cardinal and ordinal meaning of numbers, rather than learning procedures or counting strategies. In addition, Neuman's $(1987,2013)$ empirical evidence that children's different ways of experiencing numbers have consequences for their arithmetic skills provides a solid base for our investigation and our efforts to enable children to experience numbers as relations. Wagner and Davis (2010) also present the idea that numbers, or rather quantities, need to be experienced in order to become useful for calculation and understanding the value of larger numbers (that exceed the subitizing range). But while Wagner and Davis refer to the experiential basis that stems from familiar contexts, Neuman (1987) found children who fundamentally differed in their ways of experiencing (seeing) numbers, which Marton (2015) further theorized in terms of what critical aspects needed to be discerned. There seem to be some basic principles that are necessary to learn in order to understand and use numbers in arithmetic tasks, such as coordinating the ordinality in the counting sequence, the cardinality of numbers, and structuring numbers as part-part-whole relations (Baroody, 2016; Fuson, 1992).

Based on the findings described above, we adopted the use of finger patterns to represent numbers as composite sets and as a means to discern numbers' part-part-whole relations (see Fig. 1). Svenson and Sjöberg (1982) describe this strategy found among children:

... instead of counting the numbers on the fingers the whole number is immediately represented by the simultaneous marking of, for instance, 7 by showing all 5 fingers on one hand and 2 fingers on the other (...). Then, $7-3$ can be solved by taking away 3 fingers and recognizing the remaining 4 as the answer. (...) the numbers are immediately recognized when represented by one's fingers so that no counting is needed. (p. 94)

We conjecture that this strategy facilitates a conceptual understanding of numbers rather than a procedural use of fingers as countables. Since counting has long been regarded as the dominant path to development, less is known about the extent to which it is possible to

Fig. 1 A child using finger patterns to figure out the missing part in the snake game. First, the child shows the whole (10) by placing both hands on the table (not shown in figure); second, she shows the known part (6) on her fingers; and third, she sees the unknown part (4) on her fingers (by turning her left hand around or simply looking at her folded fingers) without having to count

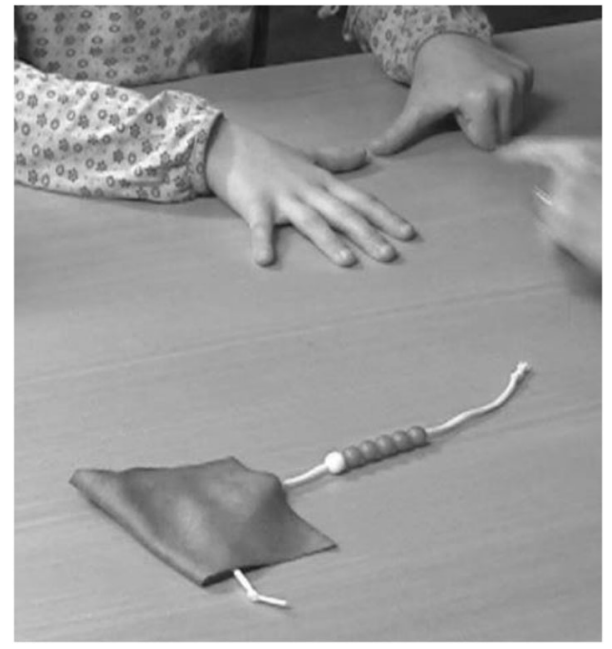


enhance 5-year-olds' arithmetic skills through experiences of numbers' part-part-whole relations. Finger patterns thus turned out to be a plausible method for aiding children in structuring numbers and operating with arithmetic tasks as relations of parts and whole. Experiencing "manyness" means embracing the idea that a group of objects can be measured by quantity (where the cardinality can be determined by counting or estimating) and experiencing this quantity as comprised of units that form a composite whole.

The activities implemented in the intervention were designed by the research team and enacted by the preschool teachers in accordance with principles of the variation theory of learning (Marton, 2015; Marton \& Booth, 1997). By creating systematic patterns of variation and invariance, the teacher can enhance possibilities for discerning critical aspects (Kullberg, Runesson Kempe, \& Marton, 2017). In the variation theory of learning, "critical aspects" are used to describe what the learner needs to discern in order to "change the way of seeing" and learn what is intended. However, what children need to discern in order to master addition and subtraction with numbers up to 10 may be different for different learners, since some children may have already discerned certain aspects while others may not yet have. The presumed critical aspects identified by the research group that were worked into the activities were as follows: numbers can be represented by fingers, numbers can be represented as different finger pattern sets, and numbers constitute a part-part-whole relation (which also can elicit the inverse relation between addition and subtraction, and commutativity).

\subsection{Activities in the intervention program}

In this study, four activities were designed and enacted for a period of 8 months. During the activities, each preschool teacher worked with one small group of children at a time (two to seven children) in a playful and interactive mode. The teacher asked probing questions to direct the children's attention to the critical aspects. The children modeled the tasks with their fingers and responded to the tasks at the same time. The children also made comments about the tasks, e.g., how they had modeled a task differently. Each of the four activities was enacted several times during the months it was implemented. The primary goal was for the children to learn to use their fingers to represent numbers and, particularly, develop finger patterns as a means of discerning and making use of numbers' part-part-whole relations (for more detail about the enactment, see Björklund et al., 2018; Ekdahl, Björklund, \& Runesson Kempe, 2019).

The statement game (October-November) The aim of the statement game (inspired by the work of Sensevy, Quilio, and Mercier (2015)) was to show that the same number can be represented differently with fingers. When playing, the children were to show how the number on a die could be represented on two hands and in different ways compared to the other children participating in the game. In the game, two critical aspects were brought to the forenumbers can be represented by fingers, and numbers can be represented as different finger pattern sets - in order to facilitate the children's development of a structural approach to arithmetic tasks using their fingers as representations of numbers in a part-whole structure.

Five-snake and ten-snake (December-March) The five- and ten-snake game was conducted with a string of beads (five in one color and five in another color, grouped together). The teacher would hide some of the beads under her hand or a cloth, leaving the rest visible. During the game, the child modeled the whole (five or ten) with her fingers and thereafter modeled the 
visible part and was asked to figure out how many the teacher had hidden under her hand. The idea was that the child should see the missing part without counting. The game emphasized the critical aspect, the part-part-whole relation of numbers, as a basis for later work with arithmetic tasks involving the use of similar part-part-whole structures to find a missing part. The game also allowed other aspects of arithmetic principles to be discerned, such as commutativity. Commutativity was possible to experience when the same numbers were used twice in the part-part-whole relation, e.g., 4/6/10 for the hidden part (4 or 6) after one another.

Finger patterns (April) In order to direct attention to the relational aspect of numbers, the teachers used finger patterns to extend the children's conceptual subitizing range (recognizing finger patterns that included an undivided 5). The children were also asked, for instance, how many fingers should be put down to make a 7 pattern from a 9 pattern and the reverse. In this manner, the relationship between 7,2, and 9 was brought to the foreground and visualized as finger patterns, where the whole was not a fixed quantity as in the snake game. The critical aspect brought to the fore during this activity was the part-part-whole relation of numbers, but now varying the quantity of the whole, which emphasized the relational nature of the parts and the whole.

Arithmetic context tasks (March-May) Arithmetic tasks were developed that included change (e.g., take away, or add a part) and comparison (difference) in quantities up to 10 , such as "Five bears were walking in the woods and three ran off; how many were left?" and "Eight tired bears came to a cottage, but there were only six beds; how many bears did not get a bed to rest in?" The children were taught to model the numbers on their fingers in the same way as in the snake game. Additional aspects that were brought forward in this activity were commutativity and the inverse relation between addition and subtraction, when applicable. These aspects were opened up for exploration through the systematic order of the tasks, e.g., in one task, three bears ran away and five were left, while in the following task five bears ran away, leaving three bears.

\section{Method}

In Sweden, 95\% of all 4- to 5-year-olds are enrolled in preschool or a similar pedagogical practice. Mathematics is usually not taught in a formalized way in Swedish preschool, but rather informally during the children's play and thematic projects. There is a curriculum for preschool with goals to strive for, such as understanding and being able to reason about the basics of numbers, quantities, patterns, and order. The assessment of children's learning is directed towards the practice's quality of enabling learning in a stimulating and safe environment (for more information about Swedish preschool, see Appendix 1). The intervention in this study is unusual, as it entails the implementation of specific activities and a systematic program over a longer period of time to reach a particular mathematical goal.

\subsection{Participating children and teachers}

A total of 103 children (at program start, aged between 4 years 10 months and 5 years 9 months, all born in 2010), from three municipalities located in similar suburban areas 
(homogeneous groups with few immigrants and with middle socioeconomic status) of a large Swedish city, participated in the study. Sixty-five children (mean age 5 years 3 months) attended the five preschools involved in the intervention program, and 38 (mean age 5 years 4 months) attended the four preschools that did not receive any particular guidance (control group). Written consent was provided by all parents/legal guardians of the children before participation. The parents did not have information about which group their children were a part of (intervention or control). Twelve teachers worked with the intervention group, and eight teachers worked with the control group. All teachers had voluntarily chosen to participate in the project.

\subsection{Meetings with the intervention group teachers}

The teachers in the intervention group had 12 meetings with two researchers over a period of 8 months. The intervention group teachers met with the researchers in two separate groups, with four preschool teachers in one group and eight in the other. The researchers discussed with the teachers presumed critical aspects of children's learning of numbers and early arithmetic. An important point of departure for the discussions involved the video-recorded interviews/pre-assessments with the children at the teachers' preschools. By viewing the different ways in which children experienced numbers, the teachers gained insight into the preschool children's understanding. The teachers and researchers worked in collaboration in an iterative process, where designed activities were enacted with the children, documented through video, and used as a basis for investigating the children's understanding and how to develop the enactment of the activities even more. The teachers uploaded videos from the enactment of the activities with groups of children regularly on a web server, giving the researchers the opportunity to analyze the enactment of the activities before meeting with the teachers. The teachers logged the dates and the children participating in the various activities. The amount of time involved in the activities differed between children.

\subsection{Meetings with the teachers working with the control group}

The eight preschool teachers working with the control group had six meetings with two researchers. During these meetings, the teachers reflected on their regular practice and activities in regard to numbers and early arithmetic skills, but without the researchers intervening in their discussions (see Björklund \& Alkhede, 2017). The teachers were encouraged to share and discuss activities they had enacted in practice by means of documentation (photo, video, text). They discussed how the activities were enacted and why they were used. For example, they discussed one game involving beads on a string, which was also used by the intervention group. However, the implementation of the game and the questions posed in regard to it differed between the groups. For instance, in the control group, the game was mostly used to count marbles, whereas in the intervention group, it was used to discern partpart-whole relations (see Fig. 1).

\subsection{Assessment of participating children}

All children were assessed three times using the same items: at the beginning of their last year in preschool (as 4- to 5-year-olds), after the intervention period, and a year after the intervention (as 6- to 7-year-olds). The two groups did not differ in their pre-knowledge (see Table 1). 
Table 1 Mean scores (M) and standard deviation (SD) on the pre-assessment, post-assessment 1, and postassessment 2

\begin{tabular}{lllll}
\hline & & Pre-assessment & Post-assessment 1 & Post-assessment 2 \\
\hline Control group $(N=38)$ & $\mathrm{M}$ & 1.61 & 3.18 & 5.42 \\
& $\mathrm{SD}$ & 1.824 & 2.091 & 2.262 \\
Intervention group $(N=65)$ & $\mathrm{M}$ & 1.69 & 4.97 & 6.32 \\
& $\mathrm{SD}$ & 1.819 & 2.271 & 1.838 \\
Within time-point comparison & $t(101)$ & -0.234 & -3.962 & -2.205 \\
& $p$ & 0.815 & 0.000 & 0.030 \\
& Cohen's $d$ & 0.04 & 0.82 & 0.44 \\
\hline
\end{tabular}

The mean score for the intervention group was 1.69 (SD 1.82) and for the control group 1.61 (SD 1.82). In the year after the intervention, no special treatment was given to either group. However, during this year, the children attended new schools with new teachers and the groups were mixed with other children.

\subsection{Assessment items}

Each individual assessment lasted about 15-20 min and was comprised of mathematical tasks within the number range 1-10. Two researchers conducted the assessments. The researchers initially observed each other in order for the assessments to be as similar as possible. The tasks were given verbally. During the assessments, no numerals were shown, and no manipulatives such as counters or similar objects were available to be used for calculation. If the child forgot the question, it was repeated. The assessments were video-recorded, with the exception of a few cases in which we only had permission to observe and audio-record. In such cases, one of the researchers conducted the assessment while the other took notes to complement the audiorecording. In this paper, we report on the eight arithmetic items used. Context as well as type differed:

A. After the child counted seven marbles in a line on the table, the researcher told the child she was going to hide the seven marbles in her two hands. The child was then asked how many marbles there could be in the left and right hands $\left(7={ }_{-}{ }_{-}\right)$.

B. After item A, the researcher opened one hand, and the child was asked to find the other part $\left(7=4+\_\right.$.

C. Oral item: You and your friend collected five shells together. You collected four of them; how many did your friend collect? $\left(5=4+\_\right)$

D. Oral item: If you have nine shells and your friend has seven shells, (...) How many more shells do you have? $(9-7=)$

E. Oral item: You have two shells and receive five more; how many do you have then? $(2+$ $5=$ )

F. Oral item: If you have ten candies and eat six of them, how many are left? $(10-6=)$

G. Oral item: You have three glasses, but are going to set the table for eight people; how many more glasses do you need? $\left(3+_{-}=8\right)$.

H. Oral item: On the morning of your birthday party, you blew up balloons. At the party, three balloons burst, and there were only six balloons left. How many balloons did you blow up that morning? $(-3=6)$. 
The individual assessments were coded for correct or incorrect answers, giving a maximum score of eight points. When no answer was given, this was coded as incorrect. In some cases, the child was not given tasks D, G, or H, and these items were coded as incorrect (see Appendix 2). The rationale for this was that when the child had previously given incorrect answers on items $\mathrm{E}$ and $\mathrm{F}$ (considered easier), the child was not asked $\mathrm{G}$ or $\mathrm{H}$ due to ethical concerns. If the child could not provide a correct answer to the question "If you have nine shells and your friend has seven shells, who has the most shells? (not included in the analysis), the child was not asked "How many more shells do you have?" (D). The number of correct answers was included in the analysis.

\section{Results}

\subsection{Comparison of intervention and control group}

We found that the learning outcomes for both the intervention and the control group (Table 1) increased in post-assessment 1 (after the intervention) and post-assessment 2 (1 year after post-assessment 1). However, the gain was higher for the intervention group compared to that of the control group. The mean for the intervention group increased from 1.69 (max. 8, SD 1.82) in the pre-assessment to 4.97 (SD 2.27) in post-assessment 1 and 6.32 (SD 1.84) in post-assessment 2 (1 year after post-assessment 1). The mean for the control group was 1.61 (SD 1.82) in the pre-assessment, 3.18 (SD 2.09) in postassessment 1, and 5.42 (SD 2.26) in post-assessment 2 .

A mixed design ANOVA was conducted, with group (intervention, control) as a between-subjects factor and assessment occasion (pre-assessment, post-assessment 1, and post-assessment 2) as a within-subjects factor. Mauchly's test indicated that the assumption of sphericity had not been violated $\left(\chi^{2}(2)=1.147, p=.564\right)$, and Levene's tests revealed no violation of the assumption of homogeneity of variance between groups on all three test occasions $\left(F_{\text {Pre-ass. }}(1101)=.021, p=.885, F_{\text {Post-ass } 1}(1101)=.769, p=.383\right.$, $\left.F_{\text {Post-ass2 }}(1101)=2.165, p=.144\right)$. As expected, the main effects for both test occasion $\left(F(2,202)=221.517, p=.000, \eta_{\mathrm{p}}{ }^{2}=.687\right)$ and group $\left(F(1,101)=7.404, p=.008, \eta_{\mathrm{p}}{ }^{2}=\right.$ .068 ) were significant, suggesting that, on average, the children's mean scores increased from one test occasion to the next and that the intervention group had better overall performance than the control group.

Most importantly, confirming our main hypothesis, the analysis shows significant interaction between group and test occasion $\left(F(2,202)=8.890, p=.000, \eta_{\mathrm{p}}{ }^{2}=.081\right)$, suggesting that the increase in learning outcome was different for the intervention and control groups. We see in Fig. 2 that, while the intervention and control groups started off with the same average results (pre-assessment), the intervention group achieved higher scores in post-assessment 1 and remained more successful after a year (postassessment 2).

The difference between means in the intervention and control groups is almost two points after the intervention (post-assessment 1; Fig. 2), and Cohen's $d$ (Table 1) indicates large effect size. The difference between groups in post-assessment 2 was smaller than immediately after the intervention, but was still almost one point. Also, Cohen's $d$ (Table 1) supports this finding, indicating medium effect size. 


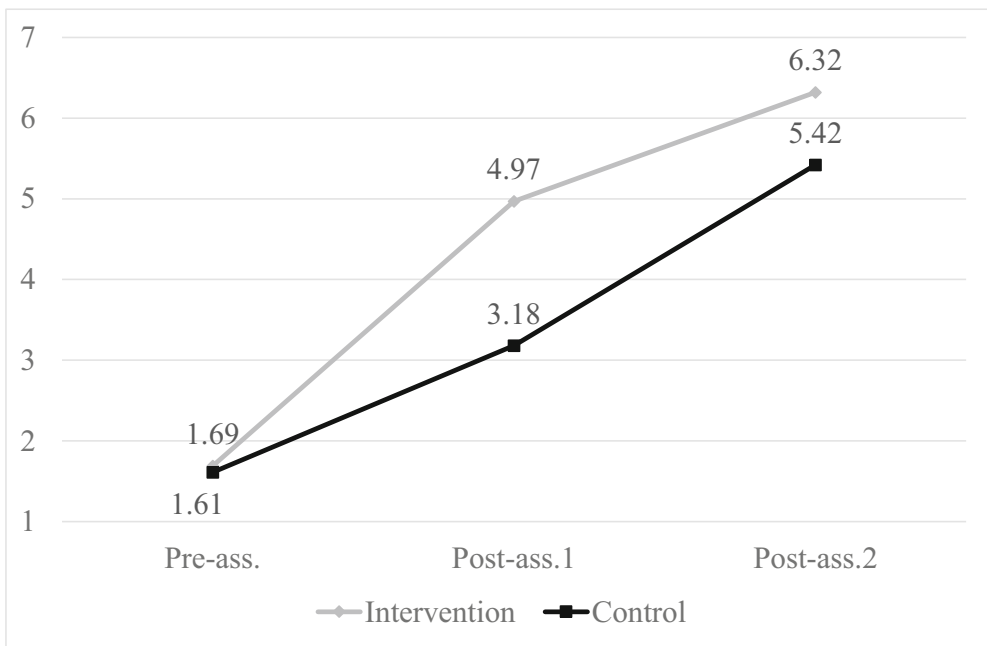

Fig. 2 Mean results for the intervention and control group in pre-assessment, post-assessment 1, and postassessment 2

\subsection{Analysis on item level}

The results show that the intervention group scored higher on all items taken together compared to the control group in both post-assessments 1 and 2 (see Fig. 3). The increase shown in post-assessment 1 compared to the pre-assessment was higher on particular items, e.g., items A (+ 47 percentage points), B (+55 percentage points), and $\mathrm{F}$ (+ 52 percentage points) for the intervention group compared to the control group $(+18,+21$, and $+24 \%$ percentage points, respectively). These items have similar features that may explain their standing out as an outcome of the intervention: they start with a known whole, and only one or neither of the parts is known. Item $\mathrm{C}$ is of similar type. However, in this case, the semantic nature of the item "You and your friend collected five shells together. You collected four of them; how many did your friend collect?" seemed to make it difficult to comprehend. We draw this conclusion as many children in both groups answered "five" on this item. We suggest that the difference between the intervention and control group on both post-assessments 1 and 2 may be due to more children in the intervention group recognizing the part-part-whole relation in the task, which made more of them able to solve the item. Item A, involving finding two unknown parts, shows a large difference between the groups, with an increase in correct answers from 19 to $66 \%$ (an increase of 47 percentage points) for the children in the intervention group and from 16 to $34 \%$ (an increase of 18 percentage points) for those in the control group. We can see that the children in the intervention group also improved more than those in the control group on items involving addition (items $\mathrm{E}(2+5)$ and $\mathrm{G}\left(3+_{-}=8\right)$ ). The children in the control group improved on all items, improving the most on those involving addition, e.g., item $\mathrm{G}$ ( +27 percentage points).

The results from post-assessment 2, 1 year after the intervention, show that there was only a small difference between the groups on items E and F (2+5 and 10-6), two seemingly straightforward addition and subtraction items (intervention group $89 \%$ and $89 \%$, control group $87 \%$ and $87 \%$ correct answers). A greater difference between the groups is found in the other types of items, for instance A, B, and C, in which the whole is known and only one or 


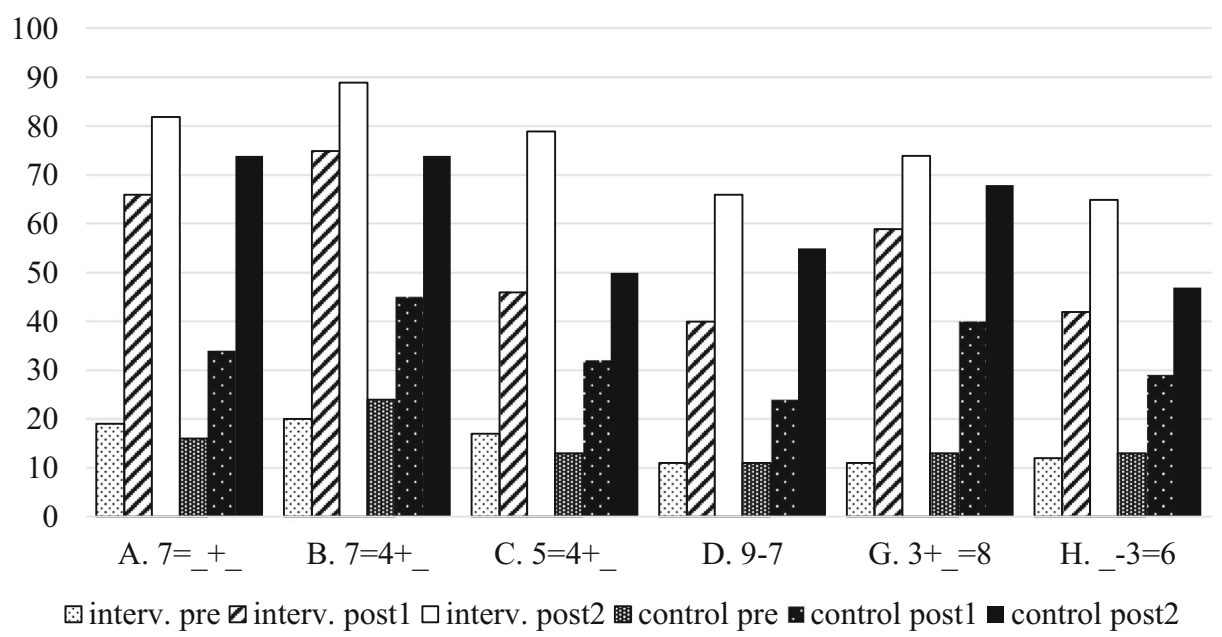

Fig. 3 Comparison of correct answers in percent on items in pre-assessment, post-assessments 1 and 2 in the intervention (interv.) and control groups. Items $\mathrm{E}(2+5)$ and $\mathrm{F}(10-6)$ are excluded in the figure; see instead text in Section 5.2

neither of the parts is known (see Fig. 3). However, the difference between the groups is smaller on items $\mathrm{A}$ and $\mathrm{B}$ in post-assessment 2 compared to post-assessment 1. A possible explanation for this is that the children may have been working with partitioning tasks during the year after the intervention (partitioning a whole into two parts, or finding the other part when one part and the whole is known). The greatest difference is on items $\mathrm{C}\left(5=4+\_\right)$and $\mathrm{H}$ $(-3=6)$, which require a comprehensive understanding of the relational structure of the whole and the parts involved. As stated earlier, these items are also more demanding semantically. Item D $(9-7)$ seems to be difficult for both groups. A possible explanation for the low result could be that the children are unfamiliar with comparison items or that they treat the subtraction as a "take away" and therefore have difficulty counting backwards seven steps.

\section{Discussion and conclusions}

For the last few decades, research on young children's learning of addition and subtraction has advocated counting and the advancement of counting strategies, as the main path for development (Carpenter \& Moser, 1982; Fuson, 1992; Verschaffel et al., 2007). Working with partpart-whole relations has been seen as a component in children's learning of addition and subtraction skills, but has not, however, been viewed as the starting point. Recently, the effects of counting strategies on later development have been debated (Cheng, 2012; Murata \& Fuson, 2006; Neuman, 2013) and concerns have been raised about children initially learning to use strategies involving counting single units, since this may hinder more advanced strategies such as decomposition (Cheng, 2012). Our study adds to the debate with research on how the use of finger patterns to structure part-part-whole relations can help preschool children develop arithmetic skills without having to rely on strategies of counting single units. Fingers offer the possibility to see the whole and the parts simultaneously. Our results show that the intervention group that was taught to use their fingers to structure part-part-whole relations 
of numbers, compared to a control group, improved their performance in addition and subtraction items significantly and to some degree on all types of items. In particular, they became better at items involving partitioning a whole into two parts, or finding one part when the whole and the other part are known. It seems as if the activities involving identifying one part of the part-part-whole relation during the intervention also helped the children learn to identify two interrelated parts of a given whole. The activities in the intervention program that encouraged the children to use their fingers to structure numbers as part-part-whole relations, we would suggest, benefited the intervention group and influenced their performance, even in more complex arithmetic context tasks (see items $\mathrm{C}$ and $\mathrm{H}$ ). We infer that having experienced the structure (whole and parts) in, for example, subtraction items (context word problems) made the children in the intervention group, to a larger extent than those in the control group, capable of figuring out the relation between the whole and the parts in more complex items as well. This suggests that the intervention group, to a larger extent than the control group, knew which numbers in the items were the parts and the whole, respectively. The calculated effect sizes offer strong evidence that the improvement in results from before the intervention to after the intervention was large (indicated by partial eta-square related to test occasion main effect), but, more importantly, the difference between the intervention and control groups was not only statistically significant but large (indicated by Cohen's $d$ ) and substantial (indicated by absolute difference in number of points).

We cannot rule out the possibility that the overall improvement from the pre-assessment to post-assessment 1 , in the control as well as the intervention group, might partly be associated with the children benefiting from the heightened attention to mathematical content in both groups (cf. Björklund \& Alkhede, 2017). The teachers in the intervention group as well as the control group most likely learned from participating in the collaborative groups together with researchers. The results suggest, however, that the intervention group performed better on particular types of additive relation tasks in post-assessments 1 and 2: the missing addend problems (see Fig. 3). These problems are reported to be difficult for young children, since they require a comprehension of the relational structure (Baroody, 2016). Although we acknowledge that other mathematical activities might have taken place, we conclude that the part-part-whole approach in the intervention group is likely to have contributed to the frequency of correct answers on these items. This is supported by results from other intervention studies that also build on a structural approach (e.g., Jung, Hartman, Smith, \& Wallace, 2013; Mulligan \& Mitchelmore, 2009).

Drawing on results from Cheng's (2012) study - that early learned strategies remain robust over time-we designed the study with two post-assessments with 1 year in between. In contrast to other studies (e.g., Jung et al., 2013; Dyson, Jordan, \& Glutting, 2013), we did not use standardized tests to measure the outcome. Furthermore, we used identical items on the three occasions. This risks some ceiling effects, which may partly explain the growth from post-assessment 1 to post-assessment 2 in both groups. Although the difference between the groups is smaller in post-assessment 2, this difference is one point and is statistically significant. This differs from other studies, in which fade-out effects are found after 1 year (e.g., Clements \& Sarama, 2011; Clements, Sarama, Spitler, Lange, \& Wolfe, 2011). Using identical items on three occasions might have jeopardized the internal validity of the study. However, we consider this to be a low risk, since the time between the assessments was 8 to 12 months. From a 6-year-old's perspective, this is a rather long time. Our results are also strengthened by the absence of dropouts in the study. 
The current study associates the growth from the pre-assessment to post-assessment 1 with data on the activities and mathematics content and principles and thus what was implemented in the intervention and control groups (Björklund \& Alkhede, 2017; Björklund et al., 2018). However, the data encourages us to conduct further qualitative analysis in terms of the strategies used by the children solving arithmetic tasks. Such an analysis might shed light on how early interventions can be traced in strategies used later.

What does having discerned the structure of part-part-whole relations entail for future learning in school? Our study shows that there was a significant difference between the intervention and control groups 1 year after the intervention, when the children had completed their first year of formal mathematics education in school (post-assessment 2). It has been argued that counting strategies children use for early arithmetic have a tendency to be used later as well, even if more advanced methods have been introduced (Cheng, 2012). We thus believe it is important which strategies are taught in early arithmetic and suggest further research on how the strategies affect future learning. Our study has implications for practice, as it suggests an alternative approach to developing preschool children's learning of early arithmetic that has proven to be powerful.

Funding information Open access funding provided by University of Gothenburg. This study was funded by the Swedish Research Council (Grant No. 721-2014-1791).

\section{Appendix 1}

Swedish preschool is a voluntary practice for children aged 1-5. It is governed by the Ministry of Education and Research and forms the first stage of the education system. The attendance rate is very high: $94 \%$ of all 4 - to 5-year olds are enrolled in some pedagogical practice, and the number of children in a preschool group is on average 15, with three teachers or child-care staff, of whom $40 \%$ have a university degree and preschool teacher exam (Swedish National Agency for Education, 2017). The preschool groups consist of both homogeneous age groups and groups of children of different ages.

There is a national curriculum that states basic values for education and practice, the preschool teachers' role as being responsible for the education conducted and the content areas and abilities that early childhood education should offer children who attend preschool. The curriculum frames the practice's goals for learning in broad terms, such as providing opportunities for children to learn the basic features of numbers, quantities, and order (Swedish National Agency for Education, 2018) and that children should be supported in using mathematics for problem solving and reasoning. Teaching is conducted by preschool teachers (Education Act, 2010:800) but there are no standards or specific knowledge goals to achieve during preschool. Mathematics is not usually taught in a formalized way, but informally during children's play and in thematic projects in various settings. The general approach is social-pedagogical, meaning that communication, interaction, and children's right to participate in democratic practices are highly valued. Compulsory education starts the year that the child turns six.

Education Act (2010). SFS 2010:800.

Swedish National Agency for Education (2017). Beskrivande data 2016. Förskola, skola och vuxenutbildning [Descriptive statistics 2016. Preschool, school and adult education]. Report nr. 452.

Swedish National Agency for Education (2018). Läroplan för förskolan. Lpfö18. [Curriculum for preschool]. SKOLFS 2018:50. 


\section{Appendix 2}

Table 2 Number of children who gave no answer or did not get the question

\begin{tabular}{|c|c|c|c|c|c|c|}
\hline \multirow[t]{2}{*}{ Task } & \multicolumn{2}{|c|}{ Pre-assessment } & \multicolumn{2}{|c|}{ Post-assessment 1} & \multicolumn{2}{|c|}{ Post-assessment 2} \\
\hline & No answer & No question & No answer & No question & No answer & No question \\
\hline $\mathrm{A}(7=++)$ & 7 & 0 & 2 & 0 & 0 & 0 \\
\hline $\mathrm{B}(7=\overline{4}+-)$ & 9 & 2 & 2 & 1 & 0 & 2 \\
\hline $\mathrm{C}(5=4+-)$ & 9 & 0 & 3 & 0 & 0 & 0 \\
\hline $\mathrm{D}(9-7=)$ & 20 & 44 & 16 & 13 & 10 & 6 \\
\hline $\mathrm{E}(2+5=)$ & 12 & 3 & 3 & 0 & 1 & 3 \\
\hline$F(10-6=)$ & 10 & 14 & 4 & 2 & 1 & 2 \\
\hline $\mathrm{G}\left(3+_{-}=8\right)$ & 7 & 34 & 7 & 6 & 2 & 2 \\
\hline $\mathrm{H}(-\overline{3}=6)$ & 7 & 39 & 6 & 9 & 2 & 9 \\
\hline Total & 81 & 136 & 43 & 31 & 16 & 24 \\
\hline
\end{tabular}

Open Access This article is distributed under the terms of the Creative Commons Attribution 4.0 International License (http://creativecommons.org/licenses/by/4.0/), which permits unrestricted use, distribution, and reproduction in any medium, provided you give appropriate credit to the original author(s) and the source, provide a link to the Creative Commons license, and indicate if changes were made.

\section{References}

Baroody, A. J. (1987). Children's mathematical thinking. New York, NY: Teachers College Press.

Baroody, A. J. (2016). Curricular approaches to connecting subtraction to addition and fostering fluency with basic differences in grade 1. PNA, 10(3), 161-190.

Björklund, C., \& Alkhede, M. (2017). Sharpening the focus on numbers and counting: Preschool educators differentiating aspects of mathematical knowledge for teaching. Mathematics Teacher Education and Development, 19(3), 117-134.

Björklund, C., Alkhede, M., Kullberg, A., Reis, M., Marton, F., Ekdahl, A.-L., \& Runesson Kempe, U. (2018). Teaching finger patterns for arithmetic development to preschoolers. Paper presented at the MADIF 11 The eleventh research seminar of the Swedish Society for Research in Mathematics Education, Karlstad.

Björklund, C., Kullberg, A., \& Runesson Kempe, U. (2019). Structuring versus counting: Critical ways of using fingers in subtraction. ZDM Mathematics Education, 51(1), 13-24.

Brissiaud, R. (1992). A tool for number construction: Finger symbol sets. In J. Bideaud, C. Meljac, \& J.-P. Fischer (Eds.), Pathways to number: Children's developing numerical abilities (pp. 41-65). Hillsdale, NJ: Lawrence Erlbaum.

Butterworth, B. (1999). The mathematical brain. London, UK: Macmillan.

Butterworth, B., Varma, S., \& Laurillard, D. (2011). Dyscalculia: From brain to education. Science, 332(6033), 1049-1053.

Carpenter, T. P., \& Moser, J. M. (1982). The development of addition and subtraction problem-solving skills. In T. P. Carpenter, J. M. Moser, \& T. A. Romberg (Eds.), Addition and subtraction: A cognitive perspective (pp. 9-24). Hillsdale, NJ: Lawrence Erlbaum.

Cheng, Z. J. (2012). Teaching young children decomposition strategies to solve addition problems: An experimental study. The Journal of Mathematical Behavior, 31(1), 29-47.

Clements, D. H., \& Sarama, J. (2007). Early childhood mathematics learning. In F. K. Lester (Ed.), Second handbook of research on mathematics teaching and learning (vol. 1). Charlotte, NC: Information Age.

Clements, D. H., \& Sarama, J. (2009). Learning and teaching early math. The learning trajectories approach. New York, NY: Routledge.

Clements, D. H., \& Sarama, J. (2011). Early childhood mathematics intervention. Science, 333(6045), 968-970.

Clements, D. H., Sarama, J., Spitler, M. E., Lange, A. A., \& Wolfe, C. B. (2011). Mathematics learned by young children in an intervention based on learning trajectories: A large-scale cluster randomized trial. Journal for Research in Mathematics Education, 42(2), 127-166. 
Dyson, N., Jordan, N., \& Glutting, J. (2013). A number sense intervention for low-income kindergartners at risk for mathematics difficulties. Journal of Learning Disabilities, 46(2), 166-181. https://doi.org/10.1177 /0022219411410233

Ekdahl, A., Björklund, C., \& Runesson Kempe, U. (2019). Teaching to change ways of experiencing numbersAn intervention program for arithmetic learning in preschool. In M. Graven, H. Venkat, A. Essien, \& P. Vale (Eds.), Proceedings of the 43 ${ }^{\text {rd }}$ Conference of the International Group for the Psychology of Mathematics Education (vol. 2, pp. 209-216). Pretoria, South Africa: PME.

Fritz, A., Ehlert, A., \& Balzer, L. (2013). Development of mathematical concepts as basis, for an elaborated mathematical understanding. South African Journal of Childhood Education, 3(1), 22-38.

Fuson, K. (1982). An analysis of the counting-on solution procedure in addition. In T. P. Carpenter, J. M. Moser, \& T. A. Romberg (Eds.), Addition and subtraction: A cognitive perspective (pp. 67-81). Hillsdale, NJ: Lawrence Erlbaum Associates.

Fuson, K. (Ed.). (1988). Children's counting and concepts of number. New York, NY: Springer.

Fuson, K. (1992). Research on whole number addition and subtraction. In D. A. Grouws (Ed.), Handbook of research on mathematics teaching and learning (pp. 243-275). New York, NY: Macmillan.

Gray, E., Pitta, D., \& Tall, D. (2000). Objects, actions and images: A perspective on early number development. Journal of Mathematical Behavior, 18(4), 401-413.

Jung, M., Hartman, P., Smith, T., \& Wallace, S. (2013). The effectiveness of teaching number relationships in preschool. International Journal of Instruction, 6(1), 165-178.

Kullberg, A., Runesson Kempe, U., \& Marton, F. (2017). What is made possible to learn when using the variation theory of learning in teaching mathematics? ZDM. Mathematics Education, 49(4), 559-569.

Marton, F. (2015). Necessary conditions of learning. New York, NY: Routledge.

Marton, F., \& Booth, S. (1997). Learning and awareness. Mahwah, NJ: Lawrence Erlbaum.

Moeller, K., Martignon, L., Wesselowski, S., Engel, J., \& Nuerk, H.-C. (2011). Effects of finger counting on numerical development. The opposing view of neurocognition and mathematic education. Frontiers in Psychology, 2, 328-336.

Mulligan, J. T., \& Mitchelmore, M. (2009). Awareness of pattern and structure in early mathematical development. Mathematics Education Research Journal, 21(2), 33-49.

Murata, A., \& Fuson, K. (2006). Teaching as assisting individual constructive paths within an interdependent class learning zone: Japanese first graders learning to add using ten. Journal for Research in Mathematics Education, 37(5), 421-456.

Neuman, D. (1987). The origin of arithmetic skills: A phenomenographic approach. Göteborg, Sweden: Acta Universitatis Gothoburgensis.

Neuman, D. (2013). Att ändra arbetssätt och kultur inom den inledande aritmetikundervisningen [Changing the ways of working and culture in early arithmetic teaching]. Nordic Studies in Mathematics Education, 18(2), 3-46.

Resnick, L. B. (1983). A developmental theory of number understanding. In H. Ginsburg (Ed.), The development of mathematical thinking (pp. 109-151). New York, NY: Academic Press.

Sensevy, G., Quilio, S., \& Mercier, A. (2015). Arithmetic and comprehension at primary school. Paper presented at the International Commission on Mathematical Instruction (ICMI) Study 23, Macau.

Sinclair, N., \& Pimm, D. (2015). Mathematics using multiple senses: Developing finger gnosis with three- and four-year-olds in the era of multi-touch technologies. Asia-Pacific Journal of Research in Early Childhood Education, 9(3).

Steffe, L., Thompson, P. W., \& Richards, J. (1982). Children's counting in arithmetical problem solving. In T. P. Carpenter, J. M. Moser, \& T. A. Romberg (Eds.), Addition and subtraction: A cognitive perspective (pp. 8389). Hillsdale, NJ: Lawrence Erlbaum.

Svenson, O., \& Sjöberg, K. (1982). Solving simple subtractions during the first three school years. Journal of Experimental Education, 50(2), 91-100.

Threlfall, J. (2002). Flexible mental calculation. Educational Studies in Mathematics, 50(1), $29-47$.

Verschaffel, L., Greer, B., \& De Corte, E. (2007). Whole number concepts and operations. In F. K. J. Lester (Ed.), Second handbook of research on mathematics teaching and learning (vol. 1, pp. 557-628). Charlotte, NC: Information Age.

Wagner, D., \& Davis, B. (2010). Feeling number: Grounding number sense in a sense of quantity. Educational Studies in Mathematics, 74(1), 39-51.

Wang, A., Firmender, J., Power, J., \& Byrnes, J. (2016). Understanding the program effectiveness of early mathematics interventions for prekindergarten and kindergarten environments: A meta-analytic review. Early Education and Development, 27(5), 692-713.

Wright, R. J. (1994). A study of the numerical development of 5-year-olds and 6-year-olds. Educational Studies in Mathematics, 26(1), 25-55.

Publisher's note Springer Nature remains neutral with regard to jurisdictional claims in published maps and institutional affiliations. 